\title{
VON HIPPEL WINNER
}

Sir Peter B. Hirsch, F.R.S. is 1983 recipient of MRS's premier honor

The Materials Research Society is honored to recognize with its Arthur Von Hippel Award the distinguished electron microscopist Sir Peter B. Hirsch, F.R.S. The award, which consists of an embedded ruby crystal, a cash honorarium and lifetime membership in the Society, will be presented at a ceremony at 5:30 p.m. Tuesday, Nov. 15, as part of the MRS Annual Meeting in Boston.

Sir Peter is Isaac Wolfson Professor of Metallurgy at the University of
Oxford. A Fellow of the Royal Society and a Fellow of St Edmund Hall, Oxford, he also is Chairman of the United Kingdom Atomic Energy Authority. His Electron Microscopy of Thin Crystals, written with A. Howie, R.B. Nicholson, D.W. Pashley and M.J. Whelan and published in 1965 , is the fundamental text on that subject, and his The Physics of Metals, Vol. II, Defects, is equally important.

Society President H.J. Leamy said in announcing the award, "Hirsch and his

\section{The Award}

The Materials Research Society's most prestigious award-and the premier honor in materials science-the Von Hippel Award, is presented to the living scientist who, in the Society's estimation, best exemplifies the originality, brilliance and diligence throughout a career that are the hallmark of science at its best; who adheres to the strictest ethical standards and highest code of professional integrity; and whose vision transcends conventional disciplines, as does the science of materials itself.

The award is named for Arthur Robert von Hippel, Emeritus Professor of the Massachusetts Institute of Technology, who was also its first recipient.

Annually, the Awards Committee of the MRS Council solicits nominations for the Von Hippel Award from among the membership and elsewhere in the community of materials scientists. The nominees are evaluated against the Society's criteria, rather than against each other; i.e., the award need not be presented in any year in which a sufficiently outstanding scientist is not put forward. Contrariwise, only a single individual can receive the prize in any year; the recipient might be chosen from among a group of distinguished scientists, at least some of whom are destined to receive the award in subsequent years.

From among the candidates it has reviewed, the Awards Committee puts forward the name of the individual it recommends, and the names of the other principal contenders for the honor. These nominees are considered in confidence by the senior officials of the Society and a recommendation made, also in confidence, to the Council itself. This body, representative of the many disciplines and institutions within the organization, makes the final selection.

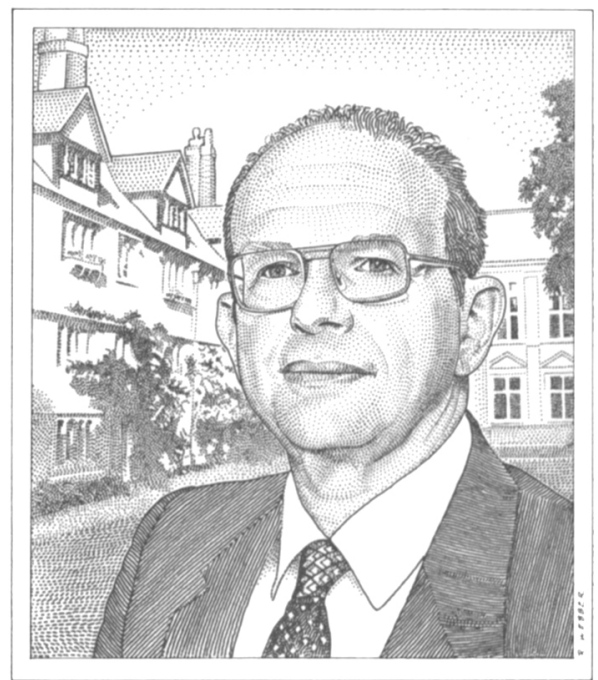

PETER BERNHARD HIRSCH

colleagues and students are largely to be credited with the elevation of the electron microscope to the preeminent position that the instrument now occupies in the study of the microstructure of materials. It is noteworthy that the Materials Research Society in its technical meetings has never failed to include among its offerings a session comprising the results of research with this instrument."

Immediate Past President C.J.M. Northrup, Jr., Chairman of the Awards Committee which nominated Sir Peter, noted, "Hirsch is the first person to observe dislocation in transmission electron microscopy. The impact made by him and his students in the field of TEM study of imperfections in materials is enormous."

\section{Education}

Peter Bernhard Hirsch was born Jan. 16,1925 , to Ismar and Regina Hirsch. Educated at Sloane School, Chelsea, he took his B.A. in 1946 from St Catharine's College, Cambridge, and became a research student at 


\section{Previous Von Hippel Winners}

The first recipient of the award was the man whose name it bears, Arthur Robert von Hippel, whose pioneering research and unfettered spirit inspired its creation. Emeritus Professor of the Massachusetts Institute of Technology, von Hippel's research in dielectrics, semiconductors, ferromagnetics and ferroelectrics resulted in the publication of two visionary books, Molecular Science and Molecular Engineering and Molecular Designing of Materials and Devices. Von Hippel studied electrophysics at the University of Goettingen, which granted him the Ph.D. in 1924. After a decade of teaching and research in Europe he joined the MIT faculty in 1936. It was in his lab that the example of scientists working cooperatively to solve the mysteries of materials from the atomic to the microstructural level first challenged the parochialism that had prevailed before and demonstrated the utility of the interdisciplinary approach which the Materials Research Society hopes to foster and embody.

The second recipient of the prize, in 1978, was W.O. Baker, Emeritus Chairman of Bell Laboratories. Baker joined Bell Labs in 1939, having received his Ph.D. in physical chemistry from Princeton the previous year. First as a member of the technical staff and subsequently in various leadership positions, he studied solid state materials and macromolecules, dielectric and dynamic mechanical properties of crystals and glasses, information processing technology, and plastics, fibers and natural and synthetic rubbers. In addition to his research, Baker has devoted himself to numerous civic, governmental and scientific committees and commissions. In 1957 Washington University, where he had done his undergraduate work, awarded him its honorary Doctor of Science degree. At least seventeen other institutions of higher education have brought honor to themselves with similar awards.

David Turnbull, Gordon McKay Professor of Applied Physics at Harvard, was the Von Hippel Award recipient in 1979. A physical chemist by training, Turnbull's research has encompassed a broad range: thermionic emission, thermodynamic properties of gases at high pressures, corrosion in non-aqueous media, diffusion in metals and kinetics of nucleation in solid state transformation. Turnbull received his Ph.D. from the University of Illinois in 1939. He began his career at Case Institute of Technology, then joined the research laboratory of the General Electric Company in 1946, where he remained until he joined the Harvard faculty in 1962.
W. Conyers Herring, 1980 recipient of the prize, is Professor of Applied Physics at Stanford University. He has had a seminal influence on materials science and solid state physics, contributing to the understanding of solid surfaces that underpins the fields of crystal growth, sintering and plastic flow at high temperatures. Together with J.K. Galt he realized and demonstrated that whiskers of high crystalline perfection would exhibit extraordinary mechanical properties. Herring received his Ph.D. from Princeton in physics in 1937. He taught at MIT, Princeton and the University of Missouri, and from 1941 to 1945 was a member of the War Research staff at Columbia University. After 30 years at Bell Laboratories, he joined Stanford in 1976.

James W. Mayer, the Society's 1981 honoree, is Francis Norwood Bard Professor of Materials Science and Engineering at Cornell University. Mayer has had a profound influence on the development of modern materials science with particular emphasis on semiconductor materials. Almost every area he has worked in has turned out to be important. For example, his research on implantation identified the damage and epitaxial regrowth phenomena long before the technique was accepted as an integral part of the semiconductor industry. He has been a pioneer in the use of ion beam techniques for materials analysis. Mayer received his Ph.D. in physics from Purdue in 1960. He was with Hughes Aircraft Company until 1967, when he became professor of electrical engineering at Caltech, where he remained until joining Cornell in 1980. Among his other accomplishments at Caltech, he was a scuba-diving instructor for a decade.

Clarence C. Zener, Emeritus University Professor of Carnegie-Mellon, received the Von Hippel Award in 1972. His contributions to the physics of metals and to mathematics are among the most fundamental and original of any 20 th-century scientist. He performed the definitive work on internal friction in solids, and provided the theoretical foundation for a line of research that resulted in the invention of the Zener diode and may be said to underlie the development of semiconductors. A graduate of Harvard, which granted him the Ph.D. in 1929, Zener accepted a series of academic appointments, interrupted by a 15-year association with Westinghouse Electric Company during which he built a research institution among the finest in the world, that culminated in his appointment as University Professor at Carnegie-Mellon in 1968. 